\title{
IS "BACKWARD MASKING" MOONTLIK? 'N EKSPERIMENTEEL-AKOESTIESE ONDERSOEK
}

Daan Wissing

Departement Algemene Taal- en Literatuurwetenskap, Potchefstroomse Universiteit vir Christelike Hoër Onderwys, Potchefstroom, 2520.

\begin{abstract}
In this article the technical possibility of backward masking is explored. The experimental-acoustic phonetic approach is followed. The objective is to see whether words, when they are heard backwards, give a coherent meaningful message. The characteristics of spoken language opposed to written language is discussed and it is shown that words are acoustically not their own mirror images when heard backwards. Especially the plosives and longer vowels get different sound qualities.In conclusion certain words and their meaningful counterparts are given and phonologically explained.
\end{abstract}

\section{INLEIDING}

Die vraag of die tegniek van die sogenaamde backward masking wel gebruik word en moontlik is, word deesdae dikwels in kerklike en ander kringe geopper. Daar word beweer dat daar in veral rockmusiek se bewoording, wanneer so in lied van agter af beluister word, versluierde boodskappe van twyfelagtige aard teenwoordig is.

Meer in die besonder word daar gevra of dit wel tegnies moontlik is. Een antwoord is dat dit weliswaar nie onmoontlik is nie, maar só duur dat dit nie in Suid-Afrika gedoen word of kan word nie. In hierdie artikel word ingegaan op laasgenoemde vraag. Dit sal vanuit die eksperimenteel-akoestiese fonetiek gedoen word. Op hierdie manier wil ook aangetoon word dat die tegnologie tot diens kan wees by die navorsing in, en beantwoording van problematiese sake soos hierdie. Met name word dit beweer dat hierdie tegniek ook in Afrikaanse rockmusiek voorkom, veral in die misbruik en belastering van die naam van die Here, en ter bevordering van die Satanisme. Dit is dus letterlik om sy Naam ontwil noodsaaklik dat helderheid hieroor verkry sal word, en dat dit, 
ook in die belang van die gelowige kinders wat hierna luister, aan die kaak gestel sal word. Per slot van rekening word dit as baie moontlik beskou dat sodanige versluierde boodskappe wel deur die onbewuste van die mens verstaan word. Laasgenoemde val egter buite die terrein van die akoestiese fonetiek, en ek wil my ook nie daaroor uitspreek nie. Eweneens is dit ook nie moontlik om met alle stelligheid te beweer, of te bewys, dat sulke betekenisvolle stukke taal willens en wetens deur die betrokke liriekskrywer ingebou is nie. Aan die ander kant is dit natuurlik ook nie onmoontlik nie dat hy/sy dit wel so bedoel het. Ook hieroor kan ek my nie uitspreek nie.

\section{DIE EIENSKAPPE VAN GESPROKE TAAL}

Taal word in die eerste plek gepraat (en gesing), en in die tweede plek geskryf. Daar is vandag nog steeds mense in die wereld wat nie kan skryf nie; tog besit hulle wel deeglik taal. Taal is dus primer klank en sekondèr skrif - 'n feit wat dikwels misgekyk word, en wat in ag gehou moet word wanneer die vrae wat in die inleiding aan die orde gestel is, beantwoord moet word. Taal bestaan bowendien uit 'n lineêr geordende reeks klanke, dit wil sê klanke volg mekaar, ietwat vereenvoudigd gestel, een vir een op, en vorm sadoende een aaneenskakelende stroom. Hierdie stroom word in die skrif deur middel van letters voorgestel. Woorde word los van mekaar geskryf, selfs al vloei dit feitlik onskeibaar in mekaar in. Vir die geletterde, dit wil sè diegene wat gewoond geraak het aan ons skryfwyse, is letters en klanke moeilik onderskeibaar, en is woorde los entiteite. Bowendien is die taalgebruiker merkwaardig onbewus van die presiese wyse waarop hy self praat - daarom is dit so moeilik om dit by taalstudente tuis te bring dat daar in groot hoeveelheid taalgebruiksreëls, en veral, wat hierdie stuk betref, klankreëls (of fonologiese reëls) onderskeibaar is in enige taal. Maar ook die presiese aard en eienskappe van die afsonderlike klanke is dikwels veel anders as wat die leek dink dit is. Wanneer woorde of groepe woorde dan van agter af beluister word (wat heel eenvoudig is: dit kan gedoen word deur eenvoudig 'n oopspoelband om te draai en dit dan af te speel), kom daar gewoonlik heel ander vorme uit as wat mens op grond van jou skrifkennis verwag. Eenvoudig gestel: 'n mens sal verwag dat as jy byvoorbeeld die woord soos omdraai, dit steeds soos bly. Dit is egter nie die geval nie. En dit is presies hierdie feit, wat deur ' $n$ slim liriekskrywer uitgebuit kan word om sy boodskap te versluier, waarop ons vervolgens ingaan. 


\section{ENKELE KLANKE EN HULLE SPIEëLBEELDE}

Soos hierbo vlugtig genoem is, klink klanke dikwels baie anders as wat verwag word wanneer hulle omgedraai word. In hierdie paragraaf word 'n aantal belangrike eienskappe van klanke wat hierdie verskynsel verklaar, behandel.

\subsection{Breking van vokale}

Lang vokale, soos oo, eu, ee en selfs aa (foneties weergegee as resp. [0: o: e: a:])word in baie variasies van Afrikaans gebreek (vergelyk byvoorbeeld Combrink \& De Stadler, 1987:34,35; De Villiers-Ponelis, 1987:44, 108). Dit wil sé dit is nie lang eenheidsvokale nie; dit eindig nie soos dit begin nie; dit is eerder diftonge (tweeklanke) met 'n relatief hoë kern en 'n neutrale afloop. oo word dus as [ua] uitgespreek (die eerste deel klink soos die oe van koel, die laaste deel soos die i van pit; [a] is die fonetiese teken daarvoor), en die ee word as [ia] uitgespreek (ongeveer ie * $i$ ). In Figuur 1 word 'n spektrogram as voorbeeld hiervan gegee:

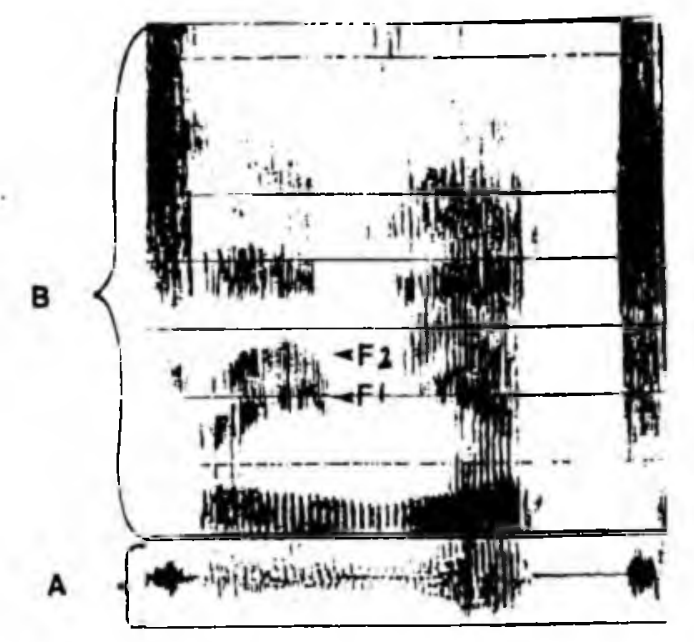


Dit is ' $n$ visuele voorstelling van die woorde sy weet. Let op na die tweede en derde formante (gemerk $F 1$ en F2) van $Y$ ([ai]) en ee ([iz] in die sonografiese (of spektrografiese) gedeelte wat met ' $n$ B aan die linkerkant gemerk is. By y krom hulle na bo; by ee na onder. Bowendien is hulle albei op dieselfde hoogte (frekwensie; respektiewelik net onder en net bo die 2000 $\mathrm{Hz}$ ). Ook die derde formante is op dieselfde hoogte. Die hoogte en vorm van formante is die belangrikste eienskappe van vokale en diftonge. Elke vokaal of diftong besit sy eie karakteristieke konfigurasie van formante. Die y en die ee is dus, ten spyte van die oënskynlike verskille tussen hulle sover dit die letters betref warmee hulle geskryf word, duidelik spieëlbeelde van mekaar. Gevolglik sal die omgekeerde van $y$ net soos ee klink, en andersom. Hierdie breking van vokale is baie belangrik wanneer dit kom by die verklaring van onverwagte resultate van omgekeerde klankreekse. Nog voorbeelde word later gegee.

\subsection{Geasporeerde stemlose eksplosiewe}

Die stemlose eksplosiewe [ $t$ ] en [ $k$ ] word soms in Afrikaans, soos ook in Engels, geaspireer, dit is, met groter spanning, klinkend op 'n stoot- of pufgeluid na die ontploffing (vergelyk ook Le Roux Pienaar, 1928:72; Van Wyk, 1977:114-115; De Villiers-Ponelis, 1987:89). Dit gebeur veral voor die vokale ie en ee (Van Wyk, 1977:117), maar ook aan die einde van woorde, selfs aan die einde van sillabes binne woorde. In Figuur 1 is daar ' $n$ voorbeeld van 'n geaspireerde [t] aan die einde van die woord weet. Die merkwaardige van hierdie klank is dat dit soos ' $n$ [s] klink as dit van agter af gehoor word. Die ooreenkoms tussen die laaste deel van die [s] en die eerste deel van die geaspireerde [t] is duidelik te sien in Figuur 1 se ossilografiese gedeelte (gemerk met ' $n$ A links aan die kant) en ook in B. Dit geld veral die kompakte swart van die dele wat in A tussen die pylkoppe lè, asook die kompakte lang swart strepe wat daarmee korrespondeer in die hoëfrekwensiegedeeltes van $B$. Afgesien van die $w$ van weet klink hierdie woord dus van agter af net soos sy - iets wat ondenkbaar is wanneer slegs na die letters gekyk word. Op in soortgelyke wyse kan aangetoon word dat 'n geaspireerde [k] van agter af soos ' $[x]$ (dit is ' $n$ g) klink. 


\subsection{Palatalisasie en labialisasie}

By nadruklike uitspraak van 'n slot-y of natuurlik ook ei) word 'n duidelike $\mathbf{j}$-klank waargeneem. Hierdie $\mathbf{j}$ is veral baie duidelik wanneer so ' $n$ woord van agter af beluister word (vergelyk ook 5.). Dit kom ooreen met onder andere die geskrewe $h$ in woorde soos heel. In tegniese terme word gesè die [h] palataliseer tot [j] (vergelyk byvoorbeeld Wissing, 1982:162; Combrink \& De Stadler, 1987). heel sal dus omgekeerd soos loi ([laj] klink, en sy soos jis ([jas]).

In die geval van labialisasie word ' $\mathrm{h}$ h as ' $\mathrm{n} w$. ([w]) soos in wé gehoor, met die gevolg dat hoor as wir [wor] uitgespreek word. Dieselfde [w]-klank kom ook aan die einde van woorde soos rou voor, sodat dit van agter af baie soos hoor klink. In omgekeerde spraak klink hierdie [w] in kombinasie met ander klanke dikwels soos die gewone bekende $w$ van byvoorbeeld wees (foneties [av]).

\subsection{Die opheffing van woordgrense}

In gewone skrif word woordgrense met wit spasies aangedui. Dit is natuurlik nie so eenvoudig nie. 'n Luisteraar wat 'n bepaalde taal nie ken nie kan nie hoor waar daardie grense in die gesproke taal lé nie. Wanneer sinne van agter af gehoor word, is hierdie feit duidelik: dikwels vorm die klanke oor daardie teoretiese grense heen nuwe eenhede. 'n Voorbeeld hiervan is trou wees, wat van agter af klink soos sy woord - die slot-[v] van wees (vergelyk 3.3) kombineer oor die woordgrens met trou on woord te vorm. Wanneer hierdie $w$ afwesig is, kan die resultaat weer anders wees (vergelyk no. 14 in 4 . hieronder).

\section{ENKELE VOORBEELDE VAN ONVERWAGTE OMKERINGS}

Hier word eers 'n aantal omkerings gegee wat werklik getoets is, en daarna sal enkele van hulle foneties-fonologies verklaar word in die lig van die algemene bespreking in 3 hierbo.

Die omkerings word hier in gewone ortografie gegee. Uiteraard klink dit dikwels nie presies so nie. Dit sal uiteraard onnatuurlik aandoen wanneer dit 
beluister word, juis omdat sommige klanke nie simmetries van aard is nie. 'n Stemlose eksplosief aan die einde van ' $n$ woord het byvoorbeeld 'n langer stilte voor die plofgedeelte as aan die begin van 'n woord. Maar die taalgebruiker is by magte om onnatuurlikhede as 't ware in sy persepsie daarvan uit te skakel, en sulke klanke met die natuurlikes te "vervang".

OORSPRONKLIKE OMGEKEERDE

$\begin{array}{lll}\text { 1. ly } & \text { heel } \\ \text { 2. myl } & \text { leem } \\ \text { 3. peer } & \text { ryp } \\ \text { 4. hoor } & \text { rou } \\ \text { 5. oom } & \text { mou } \\ \text { 6. soos } & \text { sous } \\ \text { 7. goud } & \text { twis } \\ \text { 8. oog } & \text { gou } \\ \text { 9. ook } & \text { gou } \\ \text { 10. trou wees } & \text { sy woord } \\ \text { 11. sy wees } & \text { sy wees } \\ \text { 12. gees } & \text { sy } \\ \text { 13. het } & \text { sé } \\ \text { 14. sy } & \text { hees } \\ \text { 15. sy hoort ook hoog } & \text { gou-gou trou wees } \\ \text { 16. dok } & \text { god } \\ \text { 17. dog(ter) } & \text { (ret)god } \\ \text { 18. maand } & \text { se naam } \\ \text { 19. ry } & \text { heer (here) } \\ \text { 20. se sy } & \text { Jesus }\end{array}$

5. FONOLOGIES-FONETIESE VERKLERKLARINGS VAN ENKELE OMKERINGS

Omkerings kan slegs verklaar word as die inwerking van klankreëls soos dié wat in 3 behandel is in aanmerking geneem word, veral wanneer die leser die skrifbeeld van ' $n$ woord of groepe woorde in gedagte het. 
Dit kan skematies soos volg voorgestel word:

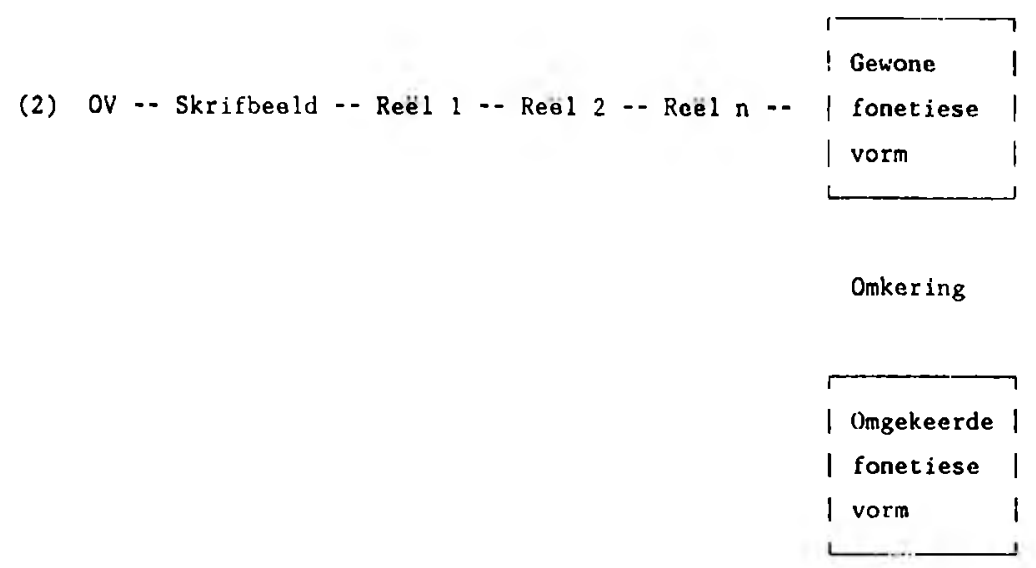

(2) moet soos volg verstaan word: die $O V$ is die onderliggende vorm of fonologiese, dieperliggende, abstrakte vorm, wat in die ortografie op 'n bepaalde wyse weergegee word. Dit is baie belangrik om daarop te let dat hierdie weergawe deur middel van letters geskied, en dat die geskrewe vorm dikwels nie ' $n$ presiese of direkte weergawe van die klankvorm van ' $n$ woord is nie. my word byvoorbeeld nie soos Mel gespel nie, maar tog word hulle eners uitgespreek. Andersom word enersklinkende woorde verskillend gespel (soos windjie en wyntjie, of leer en leër). Onderliggende vorme word in die fonologie van ' $n$ taal deur middel van fonologiese reels ( $F$-reels) verander in fonetiese vorme, dit is die warneembare, konkrete klankvorm van 'n woord. So word 'n woord soos woord onderliggend as /vo:rd/ weergegee, maar foneties as [vuart]. Dit is duidelik dat twee reëls werksaam was in die omsetting: die reël wat lang vokale breek tot tweeklanke (/o:/ tot [ua]), en 'n ontstemmingsreël, wat $/ d /$ aan die einde van die woord verander in [t]). So 'n gewone fonetiese vorm sal, wanneer dit omgekeer word, die spieëlbeeld wees van die resultaat van die omkering. 'n Eenvoudige voorbeeld is die volgende: peer se gewone fonetiese vorm is [pi ar] omgekeerd (van agter af gelees) is dit [ $r$ aip] (soos ryp), en nie reep, wat verwag word as die gewone ortografiese vorm omgekeer word nie. Dit is verklaarbaar uit hoofde van die feit dat die /e:/ deur die brekingsreël verander is tot [ia]. Die omkering van ry (naamlik Heer) kan op soortgelyke wyse verklaar word, behalwe dat daar iets bykom: Die $H$ van 
Heer is oënskynlik afwesig in die omgekeerde ry. Wel is daar ' $n j$ in plaas van die verwagte $i$ van die diftong [ai]) aan die einde van laasgenoemde hoorbaar. ry se fonetiese vorm is dus [raj]. Die $H$ van Heer word egter normaalweg ook, weens die werking van 'n palataliseringsreël, as [j] uitgespreek (vergelyk ook [jial] vir heel]. Daarom is die omgekeerde van [roj], veral as die vokaal gerek uitgespreek word, feitlik identies aan Heer. En indien ry bowendien nadruklik uitgespreek word, is daar ' $n$ asemstoot vóór die $r$ aanwesig, wat merkwaardig op 'n [a] klink. In die lig van hierdie uiteensetting is dit dus heeltemal te begrype waarom, hoe onverwags of onverklaarbaar dit ook al is, op die eerste oogopslag, ry nie yr omgekeerd is nie, mar Heer, of Here. In Figuur 2 word die spektrogramme van dié twee woorde gegee. Dit hoef nie verder verduidelik te word dat hierdie spektrogramme feitlik spieëlbeelde van mekaar is nie:

FIGUUR 2: SPEKTROGRAFIESE VOORSTELLING VAN DIE WOORDE "RY" (LINKS), EN "HERE" (REGS), WAT SPIEëLBEELDE IS VAN MEKAAR
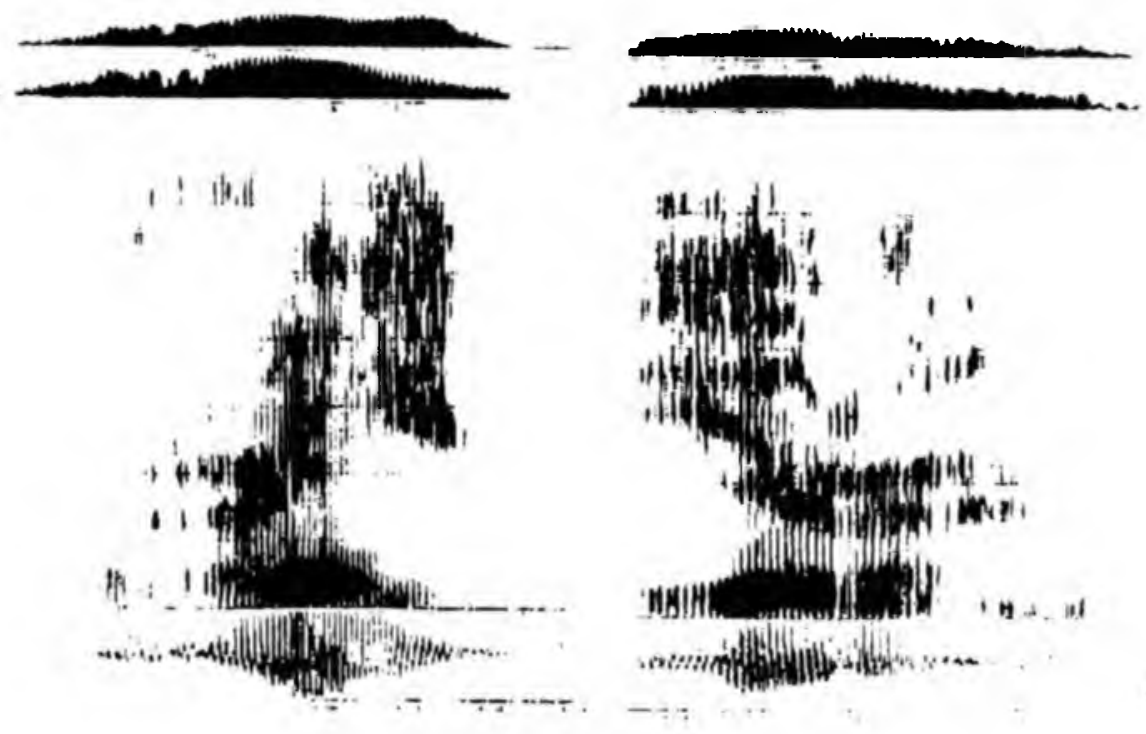

(Lees weer die uitleg by Figuur 1 hiermee saam.) 
6. SLOT

Daar is moontlik ook ander maniere waarop boodskappe in onder andere rockliedjies versluier kan word, maar dat dit op die wyse wat in hierdie artikel aangetoon is, gedoen kan word, is meer as net waarskynlik. Die moderne tegnologiese apparatuur mak dit ook moontlik om nie net by subjektiewe indrukke daaromtrent te bly nie, maar om dit objektief na te vors en aan die kaak te stel. Dit is ook die plig van die gelowige wetenskaplike om hom oor hierdie praktyk uit te spreek, en, indien dit on- of antichristelik van aard is. dit te beveg met al die middele wat tot sy beskikking is.

\section{VERWYSINGS}

1. COMBRINK, J.G.H., \& DE STADLER, L.G. 1987. Afrikaanse Fonologie Johannesburg : MacMillan.

2. DE VILLIERS, M. (Hersien deur F.A. Ponelis). 1965. Afrikaanse Klankleer. Kaapstad : Tafelberg.

3. DIE KERKBODE. 7 Julie 1989.

4. LE ROUX, T.H. \& PIENAAR, P. DE V. 1928. Afrikaanse fonetiek. Kaapstad : Juta.

5. VAN WYK, E.B. 1977. Praktiese fonetiek vir taalstudente. Durban Butterworth.

6. WISSING, D P. 1982. Algemene en Afrikaanse generatiewe fonologie Johannesburg : MacMillan. 